\title{
$\mathrm{GMAW}$ 품질분석을 위한 신호처리 방법에 관한 연구
}

\section{(A study on the welding current and voltage signal processing method for the quality evaluation of robotic GMAW)}

\author{
홍 우 헌 ${ }^{1)}$, 류 정 탁 ${ }^{2)}$ \\ (Woo Heon Hong and Jeong Tak Ryu)
}

\begin{abstract}
요 약 GMAW(Gas metal arc welding) 방법은 높은 용착률과 낮은 비용으로 인해 제조 산업분야에서 폭넓게 사용되고 있다. 이 용접방법은 제조 산업분야에서 높은 생산력을 유지하 는데 바탕이 되고, 자동화 설비 또는 로봇을 이용한 용접에 적합하다. 용접전압과 전류는 용접 비드에 많은 영향을 미친다. 그럼에도 불구하고 용접 전압과 전류는 용접 조건과 사용자 환경 에 따라 그 변화가 심하고 예측이 불가능하다. 이 값들을 직접 용접 상태 검출에 사용할 수 없 기 때문에 적절한 데이터 분석 기법이 사용되어야 한다. 본 논문에서는 용접 중에 측정된 전압 과 전류 데이터에 대하여 이동평균필터를 적용하였다. 그 결과 정상용접 상태의 전압 및 전류 의 신호특성과 비정상용접 상태의 전압 및 전류 신호의 특성을 구분할 수 있었으며 이를 통해 용접 상태 검출이 가능하게 되었다.
\end{abstract}

핵심주제어 : Gas metal arc welding (GMAW), 용접전류, 용접전압, 이동평균필터, 신호처리

Abstract Gas metal arc welding (GMAW) is currently the most widely used arc welding processes in the industry because of its high metal deposition rate, flexibility and low cost. It is attractive for high-productivity manufacturing applications and is well suited to automatic or robotic welding. Welding voltage and current have a significant impact on the weld bead. However, welding voltage and current are changed variously according to welding condition and user environment, and prediction is impossible. To determine the welding conditions, the welding current and voltage are applied to the appropriate data analysis techniques. In this paper, we used the moving average filter to the welding voltage and current data, and normal and abnormal welding waves were distinguished.

Key Words : Gas metal arc welding (GMAW), welding voltage and current, moving average filter, signal processing method

1. 서 론

1) 대구대학교 공과대학원 전자공학전공

2) 대구대학교 전자전기공학부, 교신저자(jryu@daegu.ac.kr)
용접 기술은 우리나라 전략산업 분야에서 조립완제 품의 생산에 반드시 필요한 기술이다. 그 중에서 GMAW(Gas metal arc welding) 방법은 높은 용착률 과 낮은 비용으로 인해 제조 산업분야에서 폭넓게 사 
용되고 있다[1-5]. 이 용접방법은 제조 산업분야에서 높은 생산력을 유지하는데 바탕이 되고, 자동화 설비 또는 로봇을 이용한 용접에 적합하다[3,6].

이러한 이유로 자동화 설비 또는 로봇을 이용한 용 접에서 용접 중의 변수를 측정하기 위한 시스템이 설 계되었고 활용되고 있다. 사용된 시스템으로는 비전 인식, 초음파 탐지, 방사선 탐지 등이 있다[7-11]. 이 들의 용접 결함 검출에 대한 신뢰도는 높지만 실제 작업장에서 사용하기에 시간적으로나 경제적으로 많 은 어려움이 있다. 또한 용접 중에 상태를 검사할 경 우 용접 시스템 주변에 추가적인 하드웨어를 설치해 야 하기 때문에 작업에 방해가 될 수 있다. 이런 결점 을 피하기 위해 용접전압과 전류를 검출하는 기술이 개발되었다[12-13].

용접전압과 전류는 용접 중에 고유한 변수로 측정 하기 쉽고, 이 값은 용접 비드에 많은 영향을 미친다 $[1,14,15]$. 따라서 용접전압과 전류가 적정한 상하한 값 을 유지하는 것을 관찰함으로써 용접 품질을 검출할 수 있다.

하지만 용접 전압과 전류는 용접 조건과 사용자 환 경에 따라 그 변화가 심하고 예측이 불가능하다. 용접 중에 측정된 전압과 전류는 일정하게 유지되지 않고 계속 변화한다. 이 값들을 직접 용접 상태 검출에 사 용할 수 없기 때문에 적절한 데이터 분석 기법이 사 용되어야 한다.

따라서 본 논문에서는 용접 중에 측정된 전압과 전 류 데이터들로부터 이동평균필터를 사용하여 용접 중 의 전압과 전류 신호를 처리하였다. 그 결과 정상용접 상태의 전압 및 전류의 신호특성과 비정상용접 상태 의 전압 및 전류 신호의 특성을 구분할 수 있었으며 이를 통해 용접 상태 검출이 가능하게 되었다.

\section{2. 실험방법}

용접 변수를 측정하기 위한 실험장치의 개략도를 Fig.1에 보였다. 용접전류 및 전압 파형을 측정하기 위해 사용된 오실로스코프는 텍트로닉스(Tektronix) $\mathrm{DPO} 7254$ 모델을 사용하여 초당 10,000 개의 데이터를 수집하였다. 용접기는 야스카와(Yaskawa) SR-350이 며, 용접로봇은 $\mathrm{MH} 6$ 를 사용하였다. 용접전압은 용접 기와 용접로봇 사이의 양 $(+)$ 의 단자와 음 $(-)$ 의 단자에
서, 용접전류는 홀센서(hall sensor)를 이용하여 용접 기의 음(-)단자에서 각각 측정하였다.

$\mathrm{ARC}$ 용접은 모재의 두께 및 와이어의 직경에 따라 입력 전압과 전류를 다르게 하는 것이 일반적이다. 즉 모재의 두께와 용접 속도에 맞는 최적의 용접전압과 전류가 존재한다. 실험에 사용된 용접 와이어는 직경 $1.2 \mathrm{~mm}$ 를 사용하였으며, 용접 속도는 $0.8 \mathrm{~m} / \mathrm{min}$, 용접 진행방향에 대한 토치방향은 후진법을 사용하였다. 실 험에서 사용된 모재의 재질은 냉간압연강판(Steel plate cold commercia, SPCC)이고, 모재의 두께는 $3 \mathrm{~mm}$ (이하 3t)를 사용하였다.

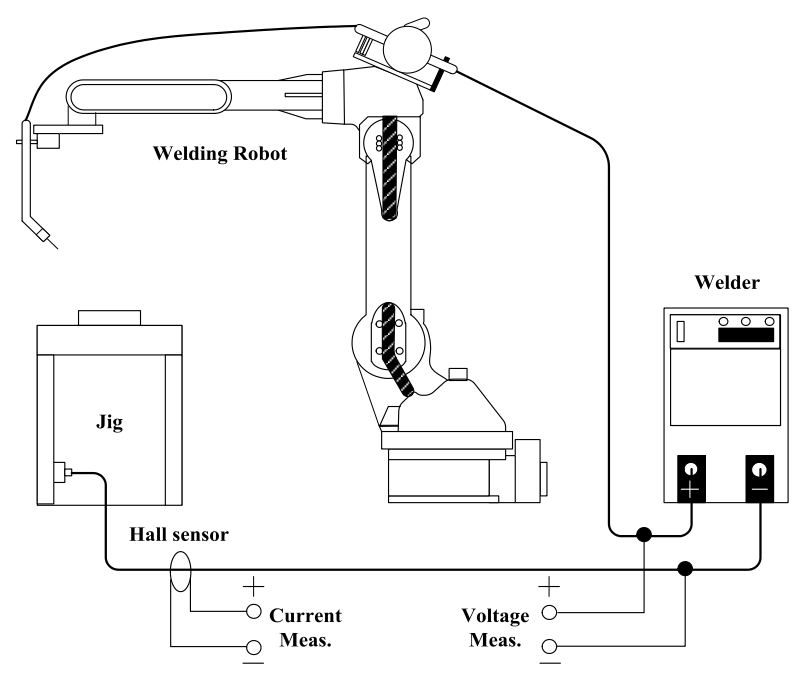

$<$ Fig. 1> Schematic diagram of the experimental apparatus for collecting the welding voltage and current data

\section{3. 실험결과 및 고찰}

먼저 최적의 용접전류 및 전압 입력 값을 결정하기 위한 방법으로는 용접 후에 형성된 비드의 모양을 육 안으로 관찰하는 외관검사법을 사용하였다.

$3 \mathrm{t}$ 모재 두께에 대한 최적의 용접전압을 찾기 위하 여 용접전류를 $180 \mathrm{~A}$ 로 고정하고, 용접전압을 $14 \mathrm{~V}$, $15 \mathrm{~V}, 16 \mathrm{~V}, 17 \mathrm{~V}, 18 \mathrm{~V}$ 로 변화하며 실험하였다. Table 1 은 용접전압 $14 \mathrm{~V}, 16 \mathrm{~V}, 18 \mathrm{~V}$ 에 대한 실험결과이다. 용접전압이 낮은 경우 $(14 \mathrm{~V})$ 전면의 용접 비드가 정상 적으로 형성되지 못하고 주변에 많은 스패터(spatter) 가 발생되었다. 또한 용접 후면 상태로 보아 용접 비 
드가 균일하게 용입 되지 않았음을 알 수 있다. 한편 용접전압이 높은 경우 $(18 \mathrm{~V})$ 전면의 비드는 정상적으 로 형성되지만 후면의 상태에서 알 수 있듯이 비드가 모재를 뚫고 형성됨을 알 수 있다. 다음으로 $3 \mathrm{t}$ 모재 두께에 대한 최적의 용접전류를 찾기 위하여 용접전 압을 $16 \mathrm{~V}$ 로 고정하고, 용접전류를 $160 \mathrm{~A}, 170 \mathrm{~A}, 180 \mathrm{~A}$, $190 \mathrm{~A}, 200 \mathrm{~A}$ 로 변화하며 실험하였다. Table 2는 용접 전류 $160 \mathrm{~A}, 180 \mathrm{~A}, 200 \mathrm{~A}$ 일 때의 실험결과이다. 용접전 류가 낮은 경우 $(160 \mathrm{~A})$ 모재에 쌓이는 용접 비드의 양 이 적고 후면의 상태로 보아 용입이 고르게 되지 않 았음을 알 수 있다. 반대로 용접전류가 높은 경우

$<$ Table 1> Weld bead shapes according to the welding voltage. (welding base metal thickness: 3t, welding current: 180A)

\begin{tabular}{l|l|c|c}
\hline $\begin{array}{c}\text { 용접 } \\
\text { 전압 }\end{array}$ & \multicolumn{2}{|c|}{ 비드(bead) 모양 } & $\begin{array}{c}\text { 육안 } \\
\text { 검사 }\end{array}$ \\
\hline \multirow{2}{*}{$14 \mathrm{~V}$} & 전면 & 불량 \\
\cline { 2 - 4 } & 후면 & & 불량 \\
\hline \multirow{2}{*}{$16 \mathrm{~V}$} & 전면 & 양호 & 양호 \\
\cline { 2 - 4 } & 후면 & & 미흡 \\
\hline \multirow{2}{*}{$18 \mathrm{~V}$} & 전면 & 0 & 불량 \\
\cline { 2 - 4 } & 후면 & & \\
\hline
\end{tabular}

$<$ Table 2> Weld bead shapes according to the welding current. (welding base metal thickness: 3t, welding voltage: 16V)

\begin{tabular}{|c|c|c|c|}
\hline $\begin{array}{l}\text { 용접 } \\
\text { 전류 } \\
\end{array}$ & & 비드(bead) 모양 & $\begin{array}{l}\text { 육안 } \\
\text { 검사 }\end{array}$ \\
\hline \multirow{2}{*}{$\begin{array}{c}160 \\
\mathrm{~A}\end{array}$} & 전면 & 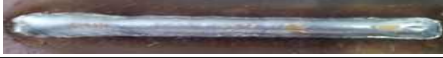 & 불량 \\
\hline & 후면 & $=$ & 미흡 \\
\hline \multirow{2}{*}{$\begin{array}{c}180 \\
\mathrm{~A}\end{array}$} & 전면 & & 양호 \\
\hline & 후면 & 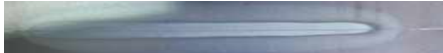 & 양호 \\
\hline \multirow{2}{*}{$\begin{array}{c}200 \\
\mathrm{~A}\end{array}$} & 전면 & a & 블량 \\
\hline & 후면 & & 미흡 \\
\hline
\end{tabular}

(200A) 와이어의 송급량이 증가하여 과도한 용접 비 드가 쌓이게 되고 스패터의 량이 증가함을 알 수 있 었다.

앞선 실험결과를 이용하여 이후는 $16 \mathrm{~V} / 180 \mathrm{~A}$ 의 용접 전압 및 전류로 실험하였다. Fig. 2는 정상용접(비드모 양이 정상으로 육안 검출됨) 일 때의 용접전류 및 전 압파형이다.
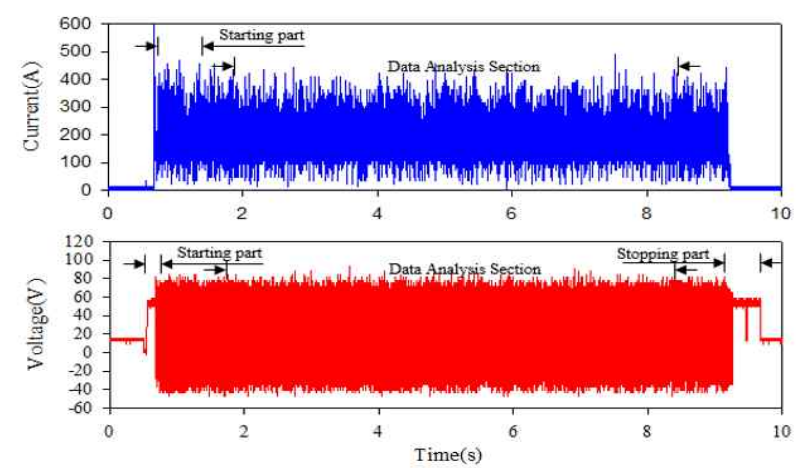

$<$ Fig. 2> The welding current and voltage waveform measured at normal welding(welding current $180 \mathrm{~A}$, welding voltage $16 \mathrm{~V}$ )

Fig. 2에 보인 바와 같이 용접전압은 시작부(starting part)와 종료부(stopping part)에서 불안정한 구간이 존재하며, 용접전류의 경우에는 불안정한 구간이 시작 부에 나타난다. 이러한 불안정한 구간은 필연적으로 존재하며, 데이터 분석 또는 결함 판정에 포함되면 $40 \%$ 이상의 오차를 발생시키는 것으로 알려져 있다 [16]. 이 오차는 용접구간이 짧을수록 더 커지며, 생산 라인에서 공정 및 품질관리가 불가능하게 된다. 따라 서 용접전압 및 전류의 파형을 통해 용접결함 상태를 분석하기 위해서는 데이터 분석 전에 불안정한 구간 을 필터링(filtering)하거나 또는 제거되어야 한다. 불 안정한 구간은 일반적으로 하드웨어나 소프트웨어 알 고리즘으로 행해진다.

정상용접과 비정상용접에 대한 용접전류 및 전압 파형의 차이를 확인하기 위하여 임의적인 비정상용접 실험을 실시하였다. 본 연구에서는 모재 두개의 간격 을 $1.5 \mathrm{~mm}$ 떨어 뜨려 놓고 비정상적인 용접실험을 하 였다. 즉 용접구간에 간격이 생기는 경우 용접 중에 측정된 전류 및 전압이 입력된 전류 및 전압과 다르 게 나타나게 된다. Fig. 3은 비정상 용접에서 측정된 
용접전류 및 전압이다. 용접을 시작한 후 5 초에서 6 초 사이에서 비정상 현상이 발생하도록 모재의 간격을 설정하였다.

따라서 5 초에서 6 초 사이에서 용접전류 및 전압 파 형에서 이상현상이 발생하여야 한다. 그러나 Fig. 3의 결과에서 볼 수 있듯이 5 초 6초 사이의 용접전류 및 전압 파형은 다른 시간대의 파형과 큰 차이를 보 이지 않는다. 이는 Fig.2와 Fig. 3에서 보인 것과 같이 측정된 파형의 관측만으로는 정상적으로 용접이 이루 어졌는지의 여부를 알 수 없다. 따라서 데이터를 정확 하게 분석하기 위해서는 적절한 데이터 분석 기법이 필요하다.
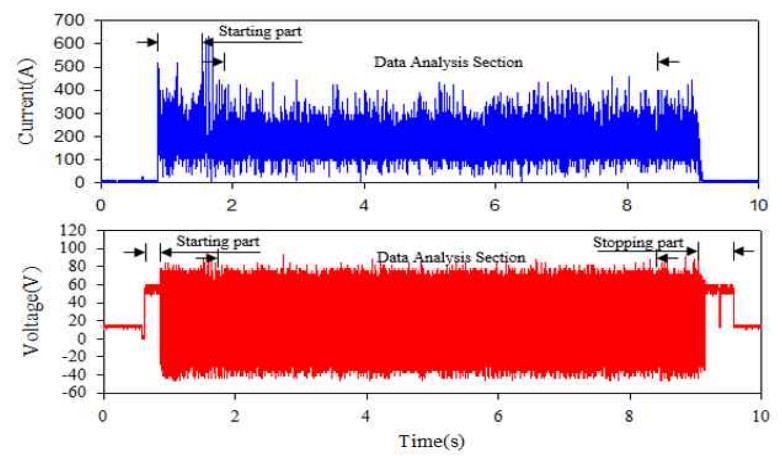

$<$ Fig. 3> The welding current and voltage waveform measured at abnormal welding(welding current $180 \mathrm{~A}$, welding voltage $16 \mathrm{~V}$ )

본 연구에서는 용접 중에 측정되는 용접전류과 전 압을 분석하기 위한 기법으로 식(1)의 이동평균필터를 이용하였다. 이동평균필터는 평균에 사용되는 데이터 의 수 $(\mathrm{N})$ 를 정해놓고 시간에 따라 $\mathrm{N}$ 을 이동하면서 평 균을 산출하는 방법이다[16]. 여기서 $\overline{x_{k}}$ 는 $\mathrm{k}$ 번째 $\mathrm{x}$ 의 이동평균이며, $\mathrm{N}$ 은 평균에 사용되는 데이터의 수를 나타낸다.

$$
\overline{x_{k}}=\frac{1}{N} \sum_{j=1}^{N} x_{k-N+j}, \quad N \leq j
$$

예를 들어 입력 데이터에 대해 $\mathrm{N}$ 이 20 인 경우의 이 동평균을 수행할 때, 81 번째와 82 번째의 이동평균은 식(2), 식(3)과 같이 산출된다.

$$
\begin{aligned}
& \overline{x_{81}}=\frac{x_{81}+x_{82}+x_{83}+\cdots+x_{98}+x_{99}+x_{100}}{N} \\
& \overline{x_{82}}=\frac{x_{82}+x_{83}+x_{84}+\cdots+x_{99}+x_{100}+x_{101}}{N}
\end{aligned}
$$

이동평균필터는 시간에 따라 입력되는 데이터의 불 규칙한 변화를 제거할 수 있는 장점이 있으며, 실제 데이터보다 완만하게 변화하므로 데이터의 추세를 알 기 쉽게 해준다. 따라서 불규칙하게 변화하는 용접 변 수의 추세를 완만하게 변환시켜 주므로 용접 상태 검 출에 유효하다.

이동평균필터에서 평균에 사용되는 데이터의 수, 즉 $\mathrm{N}$ 의 결정이 정상용접과 비정상용접을 판단하는 중요 한 요소로 작용한다. $\mathrm{N}$ 이 클수록 비정상용접 판정에 유리하지만, 하드웨어에 큰 부담을 주게 되어 시스템 의 분석 시간을 지연시키는 요인이 된다. 따라서 설정 된 결함판단 범위, 사용자 조건 그리고 용접 환경에 따라 $\mathrm{N}$ 의 값이 결정되어야 한다.

일반적으로 용접의 경우 설정용접전압에 의해 나타 나는 계측된 용접전압이 일정범위 안에 있을 때 정상 용접이 행해진다. 여기서 일정범위 내를 결함판단범위 라 한다. 이러한 결함판단 범위는 데이터 샘플수와 용 접 공정 환경에 따라 다소 차이가 있으므로, 실제 현 장에서 용접 전에 정상 용접의 표준 데이터로부터 결 정되어진다. 본 연구에서는 용접 현장에서 일반적으로 사용되고 있는 $10 \%$ 이내의 범위로 설정하였다. 예를 들어 용접전압이 $18 \mathrm{~V}$ 이고, 결함판단범위를 $10 \%$ 로 하 였다면, 결함판단 범위는 $16.2 \mathrm{~V} \sim 19.8 \mathrm{~V}$ 사이가 되며 범위 밖에 있는 전압이 계측되었을 때 용접상태는 비 정상적으로 나타난다고 할 수 있다.

용접 데이터의 이동평균은 MATLAB 프로그램으로 구현된 이동평균필터를 사용하여 산출하였다. 실제 용 접 시간은 약 8초 정도로 전체 샘플링 개수는 약 80,000 개이다. $\mathrm{N}$ 의 값이 작은 경우 결함판단범위인 $10 \%$ 를 넘게 되어 정상용접임에도 불구하고 비정상적 인 값으로 나타나게 된다. 따라서 본 연구에서는 정상 적인 용접 파형을 이용하여 다양한 $\mathrm{N}$ 의 값에 대한 파 형을 분석하였으며 그 결과 최적의 $\mathrm{N}$ 의 값으로 2000 으로 결정하였다. Fig. 4(a)는 Fig. 2의 파형을 $\mathrm{N}=2000$ 으로 하여 이동평균한 결과이다. 모든 시간대에 대하 여 점선인 결함판단범위(입력신호의 $10 \%$ )를 넘지 않 
고 있으며 이 결과는 정상용접에서의 예측된 결과와 동일하다.

Fig.4(b)는 Fig. 3의 비정상 용접 데이터에 이동평균 필터를 적용한 결과이다. 전체 샘플링 개수는 80,000 개 이며 $\mathrm{N}=2000$ 으로 하여 분석된 데이터이다. 용접전류 의 경우 결함판단 범위의 상한 값은 $204.5 \mathrm{~A}$ 이며 하한 값은 $167.3 \mathrm{~A}$ 이다. 용접전압의 경우 결함판단 범위의 상한 값(upper value)은 $19.6 \mathrm{~V}$ 이며 하한 값(lower value)은 $16.1 \mathrm{~V}$ 이다. Fig. 4(b)의 5초 6초 사이에 용접전류파형과 전압파형에서 결함판단 범위인 점선 을 넘는 파형이 검출되고 있다. 이 결과는 Fig. 3의 비정상 용접 파형에서 검출되지 않았던 결과가 본 연 구에서 제안한 이동평균 신호처리에 의해 검출이 가 능함을 의미한다. 따라서 용접전류 및 전압 파형을 이 용한 용접 결함판단을 하기 위해서는 적절한 신호처

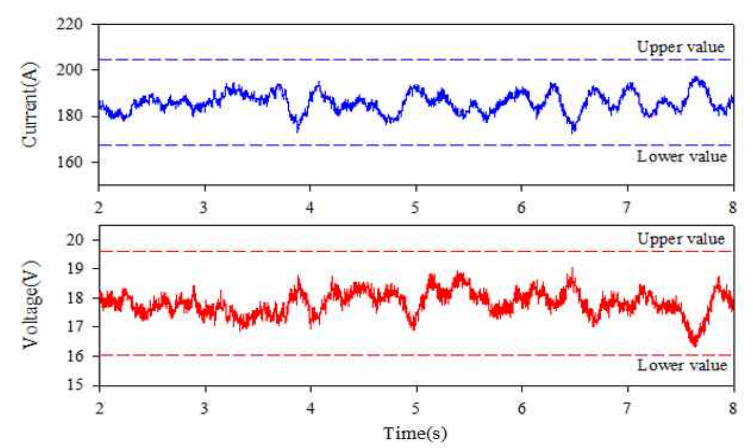

(a)

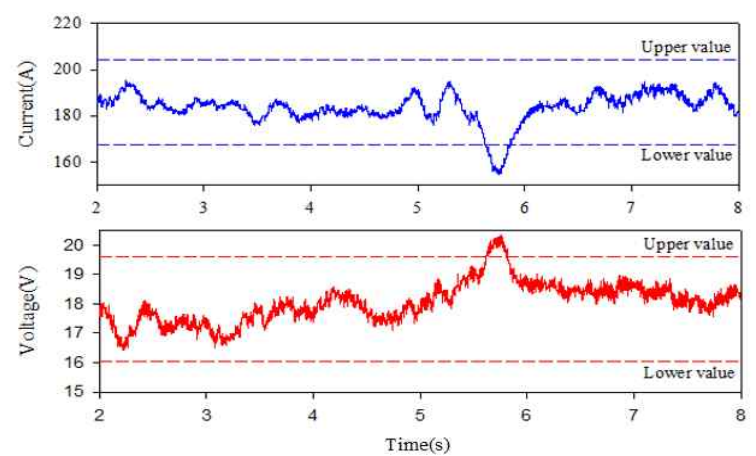

(b)

$<$ Fig. 4> Welding defect detection by the moving average filter (Sampling frequency $10 \mathrm{KHz}$ / sec, $\mathrm{N}=2000$ ) (a) the normal welding (b) abnormal welding
리가 필요하며 본 연구에서는 이동평균필터를 사용하 여 가능함을 알 수 있다.

\section{4. 결 론}

본 논문에서는 측정된 용접 변수(전압과 전류) 데이 터에 이동평균필터를 적용하여 용접 결함 상태 여부 를 실험을 통해 분석하였다. 실험을 위해 정상적인 용 접과 비정상적인(결함) 용접에 대한 용접 데이터를 수 집하였다. 데이터 수집은 초당 10,000 개이며 실제 용접 데이터는 약 80,000 개이다. 수집한 데이터에서 불안정 한 구간은 프로그램을 통해 미리 제거하였으며, 데이 터 분석은 MATLAB 프로그램으로 구현된 이동평균 필터를 사용하였다. 평균에 사용되는 데이터의 수 $(\mathrm{N})$ 의 값은 약 2000으로 하였고, 이것은 결함판단 범위가 $10 \%$ 이내가 되도록 하는 값이며 반복적인 실험을 통 해 산출되었다.

분석 결과, 신호처리 전의 측정 데이터에서는 관측 되지 않았던 용접전압 및 전류파형의 이상현상이 이 동평균필터가 적용된 데이터에서는 정확히 검출되었 다. 따라서 본 연구에서는 용접전압과 전류를 이용한 용접결함판단을 위하여 이동평균필터를 활용할 수 있 음을 알 수 있었다.

\section{References}

[1] C. S. Wu, J. Q. Gao, J. K. Hu, "Real-time sensing and monitoring in robotic gas metal arc welding”, Meas. Sci. Technol. Vol. 18, pp. 303-310, 2007.

[2] E. J. Soderstrom, P. F. Mendez, "Metal transfer during GMAW with thin electrodes and $\mathrm{Ar}-\mathrm{CO}_{2}$ Shielding Gas Mixtures", Weld. Research Vol.

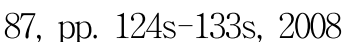

[3] A. R. D. Tipi, S. K. H. Sani, N. P.ariz, "Frequency control of the drop detachment in the automatic GMAW process", Journal of Materials Processing Technology Vol. 216, pp. 248 - 259, 2015

[4] Z.Z. Wang, "Monitoring of GMAW Weld Pool 
From the Reflected Laser Lines for Real-Time Control" IEEE Transactions on Industrial Informatics, Vol. 10, Issue 4, pp.2073-2083, 2014.

[5] M. Boselli, V. Colombo, E. Ghedini, P. Sanibondi, "Time-Dependent Modeling of Droplet Detachment in GMAW Including Metal Vapor Diffusion" IEEE Transactions on Plasma Science, Vol. 39, Issue 11, pp. 2896 - 2897, 2011.

[6] C. S. Wu, and C. B. Jia, "Statistical characteristic for detecting weld penetration defects in gas-metal arc welding", Proceedings of the Institution of Mechanical Engineers, Part B: Journal of Engineering Manufacture, Vol. 220, No. 5, pp. 793-796, 2006.

[7] R. Kovacevic, Y. M. Zhang and S. Ruan, "Sensing and control of weld pool geometry for automated GTA welding Trans", ASME-J. Eng. Indust., Vol. 117, pp. 210 - 22, 1995

[8] E. H. Cayo, S. C. A. Alfaro, "A Non-Intrusive GMA Welding Process Quality Monitoring System Using Acoustic Sensing", Sensors Vol 9, No. 9, pp. 7150- 7166, 2009.

[9] S. C. A. Alfaro, E. H. Cayo, "Sensoring Fusion Data from the Optic and Acoustic Emissions of Electric Arcs in the GMAW-S Process for Welding Quality Assessment", Sensors Vol. 12, No. 6, pp. 6953-6966, 2012

[10] Y. Xu G. Fang, N. Lv. S. Chen, JuJia Zou, "Computer vision technology for seam tracking in robotic GTAW and GMAW", Robotics and Computer- Integrated Manufacturing, Vol. 32, pp. 25 - 36, 2015

[11] H.C Wikle, S. Kottilingam, R.H Zee, B. A Chin, "Infrared sensing techniques for penetration depth control of the submerged arc welding process", Journal of Materials Processing Technology, Vol. 113, Issues 1 -3, pp. 228 - 233, 15 June 2001.

[12] M. Mousavi Anzehaee, M. Haeri, "Welding current and arc voltage control in a GMAW process using ARMarkov based MPC", Control Engineering Practice Vol. 19, Issue 12, pp.
1408-1422, 2011.

[13] Manas Kr. Bera, P. S. Lal Priya, B. Bandyopadhyay and A. K. Paul, "Discrete -time Sliding Mode Control of GMAW Systems using Infrequent Output Measurements", 2013 European Control Conference (ECC) July 17-19, 2013, Zürich, Switzerland. pp. 3736-3741.

[14] E. Karadeniz, U. Ozsarac, C. Yildiz, "The effect of process parameters on penetration in gas metal arc welding processes", Materials and Design Vol. 28, pp. 649 - 656, 2007.

[15] C. S. Wu, J. Q. Gao, X. F. Liu, and Y. H. Zhao, "Vision-based measurement of weld pool geometry in constant-current gas tungsten arc welding", Proceedings of the institution of mechanical engineers, Part B: Journal of Engineering Manufacture, Vol. 217(6), pp. 879-882, 2003.

[16] D.S. Hwang and M. Gho, "Development and application of realtime weld quality monitoring system", Journal fo KWJS Vol. 30 No. 1, pp. 44-50, 2012.

[17] Steven W. Smith, "The Scientist and Engineer's Guide to Digital Signal Processing", California Technical Publishing, 1997, Chapter 15: moving average filters pp. $277-284$. 
Journal of the Korea Industrial Information Systems Research Vol. 19 No. 6, Dec. 2014
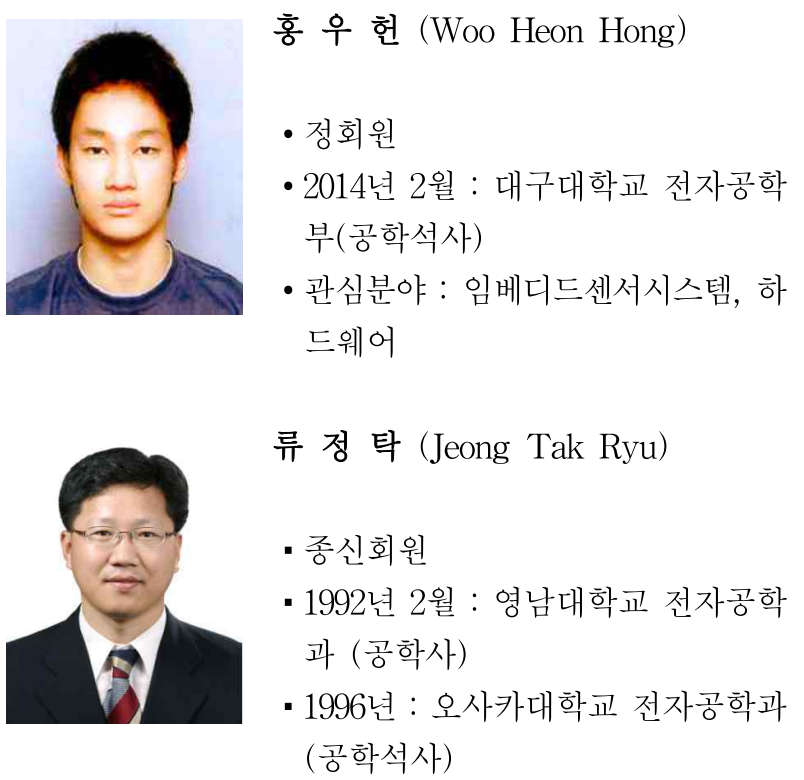

- 1999년 : 오사카대학교 전자공학과 (공학박사)

- 2000년 현재 : 대구대학교 전자공학부 교수

논 문 접 수 일 : 2014년 09월 30일 1차수정 완료일 : 2014년 11월 02일 게 재 확 정 일 : 2014년 11월 05일 